\title{
Межъязыковые омонимы в лексико-семантической группе „Религия" (на примере польского и русского языков)*
}

\author{
The interlingual homonymy \\ in "Religion's" lexical and semantic grouping \\ (on the basis of the Russian and Polish languages)
}

\begin{abstract}
The paper aims to present the types of semantic relations which hold between the interlingual homonyms existing in the semantic field of "people's spiritual life". The primary type of the relations among the studied lexical units is exclusion (the presence of a religious component in the semantics of a word of one of the studied languages and the lack of such a component in the other language). Because of the significant number of the examples of this type of relation, the words were divided into three thematic groups: 1) concepts (nассия-pasja), 2) objects (арка-arka), 3) people (лектор - lektor). The relation type of inclusion (with the shared religious semantics, one of the homonyms has an additional meaning related to this area) was observed in a few pairs (катафалк-katafalk). The relation type of overlapping (with the shared religious semantics, each of the homonyms has an additional meaning) in a given lexical field was not identified. No relation of overlapping in a given lexical field and only a few cases of the inclusion relation can prove that the resources of Russian and Polish homonymous words belonging to the religious theme of the Orthodox and Catholic Churches contrast with one another in quite an unobvious way. It is conditioned by both linguistic as well as cultural factors.
\end{abstract}

Keywords: interlingual homonymy, semantic relations, exclusion relations, inclusion relations, overlapping relations

Natalya Didenko, Uniwersytet Wrocławski, Wrocław - Polska, natalya.didenko@uwr.edu.pl, ORCID ID: https://orcid.org/0000-0003-3610-0866

\footnotetext{
* Данная статья основана на одной из глав кандидатской диссертации автора Лексико-семантический анализ русско-польских мнимых эквивалентов в сфере интернациональной лексики, написанной под руководством доктора хабилитированного Кшиштофа Кусаля. Защита состоялась в 2015 г. Представляет собой переработанный текст, обогащенный примерами из собственно славянского словарного фонда.
} 
Явление межъязыковой омонимии на примере польского и русского языков изучено особенно детально. На современном этапе изданы три лексикографических труда (Kozielewski; Kusal 2002; Szałek), написаны монографии (Stasin'ska 1990; Kusal' 2006), а также многочисленные научные статьи (Stasińska 1988; Kusal 2005; Wojan; Rutkowski), представлены обширные типологии польско-русских межъязыковых омонимов (см. Grosbart 116-130; Stasin'ska 1990: 34-42; Voân), сформулированы и описаны типы семантических отношений (см. Kusal 2005). Такое состояние научных исследований определяет один из возможных векторов дальнейшего изучения межъязыковой омонимии в польско-русском аспекте: рассмотрение этого языкового явления на примере конкретных лексико-семантических категорий, а также в сфере узко профилированных тематических групп. Подобный подход позволит более глубоко рассмотреть систематические лексико-семантические отношения польского и русского языков, проследить тенденции их развития.

Целью данной статьи является представление упорядоченных семантических связей между межъязыковыми омонимами в лексико-семантической группе (далее - ЛСГ) „Религия” польского и русского языков. Для достижения поставленной цели использовались следующие научные методы: сопоставительный с привлечением сравнительно-исторического и статистического метода. Кроме того, дополнительно применялся текстовый анализ.

Предметом исследования в статье являются польско-русские межъязыковые омонимы, которые в своей семантической структуре имеют значения религиозного характера. В ЛСГ „Религия” вошли не только термины христианства, а также лексемы, обозначающие предметы, непосредственно связанные с религиозной жизнью человека, со смертью, обрядом погребения, названия лиц - представителей духовенства и верующих.

Сущность народа во многом определяет его вероисповедание, которое неизбежно оставляет свой отпечаток в языковом пространстве. В связи с этим религиозная лексика является богатым источником как для культурологических, так и лингвистических исследований. Тот факт, что поляки являются представителями католического христианства, тогда как русские относятся к православной его ветви, не мог не повлиять на появление особенных отношений в лексике польского и русского языков. Эти отношения корнями уходят еще во времена принятия крещения восточными и западными славянами. Так, Халина Рыбицка в своей книге о судьбе заимствований в польском языке пишет следующее:

Decyzja przyjęcia chrztu za pośrednictwem czeskim, jaką podjął Mieszko I, poślubiając księżniczkę Dąbrówkę, związała Polskę z jednym z dwu centrów kulturalnych ówczesnej Europy, mianowicie z Rzymem. 
Sąsiadująca $\mathrm{z}$ nami Ruś znalazła się w tym samym czasie w kręgu oddziaływań kultury bizantyjskiej i związanych z nią wpływów języka greckiego, podczas gdy językiem liturgii rzymskokatolickiej była łacina, docierająca do nas za pośrednictwem czeskim, a nierzadko niemieckim (Rybicka 6).

В результате принятия христианства от представителей разных религиозных центров, а также самостоятельного периода развития западных и восточных славян в польском и русском языках сформировался пласт слов конфессионального характера, который передает специфику католического и православного вероисповедания в польско-русском аспекте. Эта специфика нашла свое уникальное отражение в таких лексикографических трудах, как: Podręczny stownik rosyjsko-polski i polsko-rosyjski terminów chrześcijańskich (Sztolberg-Bybluk), Leksykon chrześcijaństwa: rosyjsko-polski i polsko-rosyjski (Markunas, Uczitiel), Chrześcijaństwo: słownik rosyjsko-polski (Lewicki). Исследовательница Анна Рыгорович-Кузьма представила исчерпывающий, на наш взгляд, анализ данных словарей, каждый из которых отличается оригинальностью в описании православной терминологии через призму польского языка (Rygorowicz-Kuźma 2014, 2015). Ян Вавжиньчик, в свою очередь, в рецензии Большого русско-польского словаря (WSRP) указывал на некоторые особенности и недоработки в вышеуказанном лексикографическом произведении на примере религиозной терминологии, тем самым обращая внимание на важность этой категории слов в польско-русских языковых контактах (Wawrzyńczyk). Кроме того, неоднократно в научных статьях поднимался вопрос о функционировании православных терминов в польском языке (Rygorowicz-Kuźma 2011, 2013). В 2016 году вышла монография, написанная группой авторов (среди которых - представители духовенства), посвященная правилам функционирования православных терминов в польской языковой среде с точки зрения орфографии, пунктуации, словоизменения и словообразования, а также синтаксиса (Charkiewicz et al.). Все это говорит в пользу актуальности исследований лексических единиц с религиозной семантикой на примере польского и русского языков.

В данной статье эмпирический материал составил 51 пару межъязыковых омонимов, взятых из толковых, а также узкоспециализированных словарей, посвященных теме религии, методом сплошной выборки. На начальном этапе исследования установлено, что 27 пар относится к заимствованной лексике (то есть неславянской), причем в большинстве случаев - к интернациональному словарному фонду. 20 пар лексем имеют славянское происхождение. В четырех случаях совпадение является случайным: ciotki-четки 'różaniec', fara 'приходский костел' - фapa, pokost - nozocm 'wiejski cmen- 
tarz', ryza - риза 'ornat, oprawa obrazu, sukienka obrazu'. Проведенный анализ основывается не только на семантической структуре выбранных слов, но также учитывает фразеологические и устойчивые обороты, в которые данные лексемы входят.

Как справедливо подчеркивал Вавжиньчик, вопрос выбора специальных терминов для словарной статьи, к которым относится религиозная лексика, является весьма трудным и деликатным (Wawrzyńczyk 320). Несомненно, что при выборе переводного эквивалента для лексемы с семантикой религиозного характера необходимо привлечение внушительной базы фоновых знаний по обозначенной тематике. В связи с этим перевод рассматриваемых лексем приводится (в большинстве случаев) на основе данных из соответствующих лексикографических источников. В ситуации, когда двуязычный словарь не отражал полного объема семантической структуры слова (описанной в толковом словаре соответствующего языка), автор обращался к анализу текстов, в которых фигурировала исследуемая лексика в необходимом значении. Это стало основой для того, чтобы предложить собственный эквивалент (в редких случаях).

Вслед за польским ученым Кшиштофом Кусалем (Kusal 2005) мы выделяем следующие типы семантических соответствий среди межъязыковых омонимов: 1) исключения (при отсутствии общих значений), 2) включения (при наличии общей семантики в одном из языков функционирует дополнительное значение/значения), 3) пересечения (при наличии общих значений в обоих языках имеется различная дополнительная семантика). Необходимо отметить, что в контексте рассматриваемой группы отношения исключения будут подвергнуты незначительной модификации.

Семантические отношения, в которые входят выбранные межъязыковые омонимы, устанавливаются только на базе значений религиозного характера. В связи с этим отношения исключения рассматриваются в несколько ином ракурсе. Так, в эту группу вошли межъязыковые омонимы, которые характеризуются наличием значения религиозного характера в одном из языков и отсутствием подобного в другом языке. Здесь различаются две модели: присутствие значения религиозного характера в польском языке и отсутствие такового в русском, и наоборот. Третья модель отношений исключения является отражением классического понимания понятия „отношения исключения", которое было представлено выше, то есть в каждом из сравниваемых языков имеется значение религиозного характера, однако они не совпадают. Модели отношений исключения схематически можно представить следующим образом: 1) польский $(+) /$ русский $(-) ; 2)$ польский $(-)$ / русский $(+)$; $3)$ польский $(+) \neq$ русский $(+)$. 


\section{Семантические отношения исключения по модели польский (+) / русский (-)}

Исследование показало, что первая модель семантических отношений исключения является самой многочисленной и насчитывает 25 примеров. В связи с этим данные слова были разделены на тематические подгруппы: 1) абстрактное явление; 2) слова с предметным значением; 3) слова со значением лица.

1) Konwersja - конверсия. Польское слово имеет лексико-семантический вариант (далее - ЛСВ), который является термином в области религии: „rel. Zmiana wyznania w obrębie wyznań chrześcijańskich, zwłaszcza przejście na katolicyzm lub przyjęcie chrześcijaństwa przez wyznawcę innej religii” (USJP). Coгласно словарю Христианство: русско-польский словарь (ChSRP) у данного термина есть более употребительный вариант в польском языке nawrócenie. Однако переводным эквивалентом как для konwersja, так и для nawrócenie будет обращение (ChSRP 189). Согласно же словарю Антония Маркунаса и Тамары Учитель - переход в католическую веру (LCh 307). Второй переводной эквивалент (согласно Лексикону христианства [LCh]) является, на наш взгляд, более удачным, близким к оригиналу. Само русское слово конверсия является многозначным и употребляется в нескольких научных областях (экономике, лингвистике, в промышленной сфере и др.), но не в религии.

Profesja-nрофессия. В польском языке слово profesja имеет ЛСВ из религиозной сферы: „, religii chrześcijańskiej: uroczyste wyznanie wiary”; „publiczne złożenie ślubów zakonnych po odbyciu nowicjatu" (USJP). Переводной эквивалент для представленного ЛСВ: монашеский обет (LCh 336).

Suma - сумма (отметим, что здесь не берется во внимание русское слово „сума”, поскольку происходит оно от другого (славянского) этимона, чем рассматриваемая пара слов). Польское слово suma, в отличие от русской лексемы сумма, имеет значение религиозного характера: „rel. W Kościele katolickim: główna uroczysta msza śpiewana, z kazaniem, odprawiana w niedziele i święta (USJP). Русская же лексема в первую очередь является математическим термином: „матем. результат сложения двух или нескольких величин..." (BTSRÂ). Польскому (конфессиональному) значению в русском языке соответствует слово обедня (LCh 348).

B данную подгруппу также войдут межъязыковые омонимы с абстрактным значением: łaska 'łaska Boża - милость Божья' - ласка; anamneza 'анамнесис' - анамнез; pryma 'первый литургический час' - прима; tercja 'третий литургический час' - терциия; stacja 'этап крестного пути' - станциия; procesja 'крестный ход, церковное шествие' - процессия; królestwo (Królestwo Nie- 
bieskie albo Воże - Царство/Царствие Небесное или Божье) - королевство; pogrzeb 'похороны' - погреб; palma (Niedziela Palmowa - Вербное Воскресенье) - пальма.

2) Figura - фигура. Русская лексема не имеет значений, связанных с религией, в то время как польское слово обладает следующей семантикой: „роsąg, krzyż, kapliczka, umieszczone przy drogach, na placach itp., będące przedmiotem kultu" (USJP). В русском языке такое распятие обычно называется придорожным крестом (WSPR I: 208). Здесь также можно привести еще один эквивалент - придорожная часовня (N. D.).

Korona - корона. В польском языке для обозначения такого обязательного предмета церковного венчания, как венеи, используется слово korona. В русском же языке лексема корона как символ означает лишь власть монарxa (BTSRÂ). Кроме того, в польском языке функционирует фразеологическая единица korona cierniowa („męka, cierpienie, ból, które są czyimś udziałem [...]" [USJP]), которая в русском языке передается как терновый венеи (LCh 307).

Ampuła/amputka - ампула. Польская лексема amputka имеет значение, которое отвечает критериям данного исследования: „rel. Dzbanuszek ze szkła lub metalu do podawania kapłanowi wody i wina podczas mszy, ampuła" (USJP). Русское слово такой семантикой не обладает. Эквивалентом польской лексемы amputki в приведенном выше значении в русском языке является словосочетание священные сосуды (LCh 271).

B данную подгруппу межъязыковых омонимов с предметным значением также войдут слова: karawan 'катафалк' - караван; arka 'ковчег' - apкa; purpura 'порфира/багряница' - nypnyp; relikwie 'мощи' - реликвии.

3) Probant-nробанд. Данные слова являются моносемантами. Значение русской лексемы: „исходное лицо в рассматриваемой генеалогии (родословной)" (NSIS под Пробанд). Как видно из определения, слово не имеет религиозной семантики, тогда как польская лексема probant означает следующеe: „rel. Kandydat do zakonu w okresie probacji; nowicjusz” (USJP). Согласно Большому польско-русскому словарю данное слово на русский язык можно перевести как послушник (WSPR II: 161).

Lektor - лектор. Польское слово имеет следующий ЛСВ: „rel. kleryk, który otrzymał święcenia lektoratu; osoba świecka uprawniona do czytania lekcji podczas nabożeństwa” (USJP). Русским эквивалентом для данного значения является лексема чтеи (LCh 311).

Król - король. В польской католической традиции отмечается праздник Święto Trzech Króli („,rel. święto katolickie przypadające 6 stycznia, w którym czczone jest objawienie się Jezusa Chrystusa" [USJP]). В русском языке польскомy królowie соответствует слово волхвы. Данный праздник отсутствует 
в православном календаре, кроме того, православная церковь не считает их царями, не подсчитывала их число, не давала им имена и не вписывала их в доктрину (РЀ под Boлxвbl). Разница в восприятии текстов Евангелия отразилась не только на культуре, но и на языке: русское слово король лишено религиозной семантики (BTSRÂ).

В данную подгруппу межъязыковых омонимов со значением лица также войдут слова: dziekan 'благочинный' - декан, zakonnik 'монах' - законник, patron 'покровитель при крещении' - патрон.

\section{Семантические отношения исключения по модели польский (-) / русский $(+)$}

В группу межъязыковых омонимов с отношениями исключения по модели, когда в русском языке присутствует значение религиозного характера, а в польском - нет, вошли только 9 примеров, которые аналогично можно поделить на три тематические группы: 1) абстрактное явление; 2) слова с предметным значением; 3) слова со значением лица.

1) Carstwo - царство. В данной омопаре польская лексема не обладает семантикой религиозного характера, что зафиксировано в лексикографическом труде Станислава Дубиша. В словарной статье иарство в Большом толковом словаре русского языка можно обнаружить устойчивое выражение Царство небесное в значении 'рай' (BTSRÂ). Польским эквивалентом в данном случае будет сочетание Królestwo Niebieskie (WSPR I: 362).

Kończyna - кончuна. Принципиальным образом разошлись значения в данной омопаре. Семантика польского слова не связана с религиозной сферой, тогда как русское слово означает следующее: „высок. смерть” (BTSRÂ). Соответствием для русской лексемы в польском языке будет слово zgon (WSRP I: 496).

Wierzba-вербa. Это последний пример в данной подгруппе. Здесь, как и в предыдущем случае, омонимия прослеживается на уровне устойчивого сочетания Вербное Воскресенье, которое на польский язык необходимо переводить как Niedziela Palmowa (LCh 43). Необходимо отметить, что польскому языку известно также определение Niedziela Wierzbna, тем не менее более употребляемым является термин Niedziela Palmowa. Название христианского праздника в польском языке является отражением фактов, описанных в Библии - вхождение Спасителя в Иерусалим, приветственное возложение пальмовых ветвей народом в знак признания Сына Господа. В русском же языке принялось название праздника, которое основано на обычае, сложившемся в силу того, что в холодном климате славянских государств пальмы не 
росли. Их заменили вербами, что и отразилось в языке. Интересными в данном ракурсе являются рассуждения учителя церкви, выдающегося западного теолога Илария Пиктавийского, относительно текста пророка Исаии:

Drzewa wierzbowe mają taką właściwość, że choćby były uschnięte, po podlaniu ich wodą odzyskują zieloność. Ich obcięte gałązki, wetknięte w wilgotną ziemię, puszczają głęboko korzenie. Natura tego drzewa, jak zaręcza to świadectwo proroka, oznaczać ma ludzi świętych i wierzących... (Forstner 180).

Таким образом, верба, как и пальма, является одним из символов христианской веры. Поэтому замена одного понятия другим в номинации христианского праздника является вполне закономерным явлением.

2) Wertepy - верmen. Русская лексема имеет значение религиозного характера: „в старину: кукольный театр [...] для уличных представлений на библейские и комические сюжеты" (BTSRÂ). Согласно двум переводным словарям на религиозную тематику, используемым в данной работе, русское слово имеет еще одно значение: „место (пещера), где родился Христос” (ChSRP 83). Переводными эквивалентами для данных двух значений будут: szopka, jasetka; stajenka (betlejemska) (ChSRP 83) / grota, pieczara (LCh 44).

Sklep - склеп. Польское слово, заимствованное русским языком посредством украинского (ÈSRÂ 641), приобрело в новой языковой среде значение религиозного характера: „[...] подземное [...] помещение, в котором устанавливаются гробы” (BTSRÂ). Эквивалентами в польском языке могут служить лексемы: grobowiec, krypta (WSRP II: 452).

В данную подгруппу войдет также омопара: wieniec - венеu 'korona' (терновый венец - korona cierniowa).

3) Pastwa-nacmвa. Польская лексема является архаизмом, сейчас встречается в основном в устойчивом сочетании rzucić kogoś na pastwę losu. Тогда как русское слово имеет следующее значение из религиозной сферы: „религ. верующие, живущие в одном приходе [...], прихожане” (BTSRÂ). Переводной эквивалент: parafianie, wierni (WSRP II: 16).

Bohomaz - богомаз. Польское слово, в отличие от русского, не имеет семантики религиозного характера. Русская же лексема означает следующее: „ycтар. иконописец” (BTSRÂ). Согласно Лексикону христианства переводным эквивалентом в польском языке будет malarz ikon (LCh 32).

$P a p a-n a n a$. Польская лексема является омонимичной, в анализе рассматривается только омоним со значением „ојсіес, tatuś” (USJP) в связи с общей этимологией с русским словом. Русская лексема имеет следующую семантику: „верховный глава римско-католической церкви” (BTSRÂ). В польском же языке для данного значения функционирует форма, заимствованная из чешского языка - papież (USJP). 


\section{Семантические отношения исключения по модели польский $(+) \neq$ русский $(+)$}

В семантических отношениях исключения можно выделить также третью модель, при которой в каждом из языков имеются значения религиозного характера, однако они не совпадают. Это межъязыковые омонимы: grób 'могила' - гроб 'trumna', bursa 'мешочек для Причастия' - бурса 'духовное училище'; zakon 'монашеский орден' - закон (Закон Божий - 1. Prawo Boże, 2. Religia - предмет в школе); kadzidto 'ладан' - кадило 'kadzielnica'; chrzest крещение' - крест 'krzyż'; bożnica 'синагога, молельня' - божницุa 'półka lub szafka ze świętymi obrazami'; klątwa 'анафема' - клятва 'przysięga'; zapowiedź ‘объявления с амвона о помолвке' - заповедь 'przykazanie, nakaz'.

\section{Семантические отношения включения}

Семантические отношения включения в данной работе наблюдаются в тех случаях, когда межъязыковые омонимы имеют общее значение религиозного характера, однако также в одном из языков имеется дополнительный ЛСВ из той же тематической категории. Здесь можно выделить две модели: 1) когда в польском языке семантическая структура лексемы шире; 2) когда в русском языке семантическая структура лексемы шире. Схематически модели в отношениях включения можно представить следующим образом: 1) польский > русский; 2) польский < русский.

К примеру, пара katafalk-катафалк имеет общее значение: „возвышение с траурными украшениями, на которое ставится гроб при отпевании в церкви или при гражданской панихиде" (BTSRÂ). Кроме того, русское слово имеет дополнительную семантику: „погребальная колесница в похоронной процессии" (BTSRÂ). Польский эквивалент - karawan (WSRP I: 462). Здесь представлена модель: польский < русский.

Пара интернационализмов konfesja - конфессия совпадает в основном значении: „ksiażk. wyznanie, wyznawana religia” (USJP) - „вероисповедание” (BTSRÂ). Однако польское слово семантически богаче и имеет ряд значений, отсутствующих в русском языке: „rel. szt. przedsionek prowadzący do grobu męczennika znajdującego się pod ołtarzem głównym (1); od VIII w.: grobowiec z jego relikwiami, znajdujący się wewnątrz kościoła (2); ozdobna obudowa grobu męczennika w formie baldachimu (3)" (USJP). Лексикографические переводные издания на религиозную тематику данной семантики не фиксируют. Первое значение из представленных выше ('przedsionek') является особенно трудным в передаче на русский язык. Из проанализированных 
нами интернет-текстов, посвященных собору Святого Петра в Ватикане (см. Список источников), можно сделать вывод, что данная семантика не имеет в русском языке конкретного лексического выражения. Если в польскоязычных текстах для обозначения захоронения мощей Святого Петра используется слово konfesja, то в русскоязычных текстах на аналогичную тематику встречаются два варианта передачи значения „przedsionek prowadzący do grobu męczennika" (USJP): латинское слово confessio, а также метафорическое определение - окошечко. В таком случае одним из возможных переводческих решений было бы описательное истолкование понятия: в католических храмах - вид захоронения мощей святых, представляющего собой углубление с окошечком, через которое верующий может обратиться с молитвой к Святому (N. D.).

Второе значение лексемы konfesja из вышепредставленных на русский язык переводится по-разному в зависимости от формы и объема гроба: гроб мученика, рака, мощевик. Для третьего ЛСВ в качестве переводного эквивалента, как нам представляется, может послужить слово киворий (или алтарная сень) - „куполоподобная сень над престолом на столбах” (РЕે под Кивоpuй). Данный пример (konfesja - конфессия) иллюстрирует модель польский $>$ русский.

Интересна омопара pasja - пассия. Толковые словари русского языка не отмечают религиозной семантики слова пассия, тогда как в текстах, посвященных Великому посту в Православной энциклопедии можно найти следующую информацию:

Вечером по пятницам или по воскресеньям первых 4 седмиц В. п. (Великого поста N. D.) в некоторых приходах и монастырях совершаются пассии, представляющие собой вечерню с акафистом Страстям Христовым и чтением Евангелия о Страстях; пассии не указаны в Типиконе и были первоначально установлены в 1-й пол. XVII в. в Киеве святым Петром (Могилой) по аналогии с лат. практикой (пассия от лат. passio - страсть) (PЀ под Великий пост).

Таким образом, польская и русская лексемы имеют общую семантику. Однако польское слово дополнительно имеет значение из области искусства, относящееся непосредственно к религиозной тематике: „szt. cykl scen obrazujących mękę Chrystusa (od wjazdu do Jerozolimy do Zmartwychwstania), będący tematem przedstawień religijnych w malarstwie i rzeźbie”, „muz. utwór wokalny lub wokalno-instrumentalny, o charakterze dramatycznym, oparty na tekście zaczerpniętym z ewangelicznego opisu męki Chrystusa" (USJP). Согласно словарю Романа Левицкого, данные значения необходимо переводить как Страсти Господни (Христовы). Правильность данного утверждения подтвердилась в переводе заглавия известного фильма Мела Гибсона (англ. The 
Passion of the Christ: pус. Страсти Христовы, польск. Рasja). Здесь представлены семантические отношения включения по модели польский $>$ русский.

В данную группу можно также отнести пары слов: patron (общее значение: ‘покровитель города, общины'; дополнительное: ‘при крещении - покровитель') - nатрон; pascha - Пасха (общие значения: 'праздник в иудаизме и сладкое кушанье'; дополнительное: 'Wielkanoc'). В разговорной речи русское слово Пасха лучше всего заменить на польское Wielkanoc, тогда как в процессе перевода (в зависимости от его вида: узкоспециальный или литературный) в качестве эквивалента может быть использована лексема Pascha.

\section{Выводы}

Семантические отношения в сфере польско-русских межъязыковых омонимов на примере ЛСГ „Религия” имеют систематический характер. Отличает их четко прослеживаемая конфронтация значений, которая отражена в семантических отношениях исключения. Количество примеров, которые однозначно входили в обозначенные группы, составило 42 пары из 51. Семантические отношения включения представлены лишь в пяти примерах. Четыре межъязыковые омопары являются результатом случайного совпадения форм с разной этимологией.

Статистические данные показывают, что в группе межъязыковых омонимов с отношениями исключения по модели польский $(+)$ / русский (-) большая часть примеров - слова заимствованные, относящиеся к международному словарному фонду с первоначальным этимоном, восходящим к латыни. В группе омонимов по модели польский (-) / русский (+) все примеры (кроме одного: papa - nana) имеют славянское происхождение. Такое соотношение является свидетельством принадлежности говорящих на русском и польском языке к разным ветвям христианства - католичеству и православию, история становления первого направления тесно связана с латынью и Римом, в то время как история второго - с Византией и старославянским, греческим языками. Межъязыковые омонимы с отношениями исключения по модели польский $(+) \neq$ русский $(+)$, отличающиеся семантическим наполнением, все относятся к славянскому словарному фонду. Это является свидетельством как общего праславянского периода развития, последующими постоянными (с разными периодами интенсивности) контактами, так и самобытным развитием каждого из языков.

Семантические отношения включения образовались на основе лексики заимствованной, в большей части - интернациональной. Вероятнее всего связано это с выборочным характером процесса заимствования, когда язык, 
не нуждающийся в дополнительном ЛСВ по причине наличия славянской (иногда - греческой) отдельной словоформы или по причине ненадобности значения (как это было со словом konfesja), не присваивает полной семантической структуры иностранного слова.

Таким образом, межъязыковые омонимы в тематической группе „Религия” имеют свои особенности: входят в разветвленную сеть семантических отношений, которые обусловлены факторами как из области лингвистики, так и собственно культуры.

\section{Библиография}

Charkiewicz, Jarosław et al. Specyfika polskiej terminologii prawosławnej. Koncepcja normatywizacji pisowni. Białystok, Wydawnictwo Uniwersytetu w Białymstoku, 2016.

Forstner, Dorothea. Świat symboliki chrześcijańskiej. Per. Wanda Zakrzewska, Paweł Pachciarek, Ryszard Turzyński. Warszawa, Instytut Wydawniczy PAX, 1990.

Grosbart, Zygmunt. Teoretyczne problemy przektadu literackiego w ramach języków bliskopokrewnych (na materiale języka polskiego i języków wschodniosłowiańskich). Łódź, Uniwersytet Łódzki, 1984.

Kusal, Krzysztof. „Tipy semantičeskih otnošenij v sfere russko-pol'skoj mež"âzykovoj omonimii”. Žmogus ir žodis. Svetimosios kalbos. Mokslodarbai, 3, 2005, s. 23-29.

Kusal', Kšištof. Russko-pol'skaâ mež" âzykovaâ omonimiâ kak leksikografičeskaâ problema. Sankt-Peterburg, Izdatel'stvo Sankt-Peterburgskogo universiteta, 2006.

Rutkowski, Krzysztof. „Polsko-rosyjskie homonimy i paronimy międzyjęzykowe - propozycja klasyfikacji”. Studia Wschodniostowiańskie, 12, 2012, s. 305-319.

Rybicka, Halina. Losy wyrazów obcych w języku polskim. Warszawa, PWN, 1976.

Rygorowicz-Kuźma, Anna. „Nazwy nabożeństw prawosławnych w języku polskim”. Studia Wschodniosłowiańskie, 13, 2013, s. 117-125.

Rygorowicz-Kuźma, Anna. „Terminologia prawosławna w języku polskim (na przykładzie nazw osób duchownych)”. Acta Polono-Ruthenica, 16, 2011, s. 403-413.

Rygorowicz-Kuźma, Anna. „Terminologia prawosławna w rosyjsko-polskich słownikach ogólnych". Acta Polono-Ruthenica, 19, 2014, s. 261-271.

Rygorowicz-Kuźma, Anna. „Terminologia prawosławna w rosyjsko-polskich słownikach specjalistycznych". Studia Wschodniostowiańskie, 15, 2015, s. 405-414.

Stasin'ska, Polina. Mež"âzykovaâ omonimiâ v russko-pol'skom sopostavlenii. Zielona Góra, Wydawnictwo Wyższej Szkoły Pedagogicznej, 1990.

Stasińska, Polina. „O nekotoryh tipah semantičeskih otnošenij v predelah russko-pol'skih omonimov”. II Spotkania Językoznawcze ,, W kręgu semazjologii, leksykologii i terminologii”: materiały z Międzynarowowej Konferencji w Opolu-Szczedrzyku 12-13 września 1986 r. Red. nauk. Stanisław Kochman. Opole, WSP, 1988, s. 263-267.

Szałek, Marek. Stownik homonimów rosyjsko-polskich. Poznań, Ars Nova, 2004.

Sztolberg-Bybluk, Mirosława. Podręczny słownik rosyjsko-polski i polsko-rosyjski terminów chrześcijańskich. Toruń, Wydawnictwo Naukowe UMK, 1994.

Voân, Katažina. „Âvlenie omonimii i sravnitel'noe âzykoznanie (na materiale russkogo, pol'skogo i finskogo âzykov)". S"postavitelno ezikoznanie / Sopostavitel'noe âzykoznanie / Contrastive linguistics, 29, 2004, s. 24-35. 
Wawrzyńczyk, Jan. „Wyrazy i zwroty związane z życiem religijnym w «wielkiej» leksykografii rosyjsko-polskiej”. Acta Polono-Ruthenica, 1997, s. 315-322.

Wojan, Katarzyna. „Zjawisko homonimii międzyjęzykowej na przykładzie języków: polskiego, rosyjskiego i fińskiego". Wokót homonimii międzyjęzykowej. Red. Małgorzata Majewska. Warszawa, Wydawnictwo Uniwersytetu Kardynała Stefana Wyszyńskiego, 2017, s. 41-69.

\section{Словари и источники}

Ciao, Bella Italiâ. Sobor Svâtogo Petra. Vatikan. Web 20.10.2019. http://www.ciao-bellaitalia. com/2013/11/blog-post_30.html.

Dubisz, Stanisław, red. Uniwersalny słownik języka polskiego. Edycja komputerowa, CD-Rom, 2001.

Fasmer, Maks. Ètimologičeskij slovar' russkogo âzyka. Per. i red. Oleg Trubačev. Moskva, Progress 1971.

Gosudarstvo grad Vatikan. Sobor svâtogo Petra. Web 20.10.2019. https://vaticanstate.ru/sobor-svyatogo-petra/.

Hessen, Dymitr, Ryszard Stypuła. Wielki słownik polsko-rosyjski, t. I, II. Warszawa, Wiedza Powszechna, 1996.

Kozielewski, Ignacy. Słownik wyrazów o podobnym brzmieniu a odmiennym znaczeniu w języku rosyjskim i polskim. Warszawa, Państwowe Zakłady Wydawnictw Szkolnych, 1959.

Kusal, Krzysztof. Rosyjsko-polski słownik homonimów międzyjęzykowych. Wrocław, Wydawnictwo Uniwersytetu Wrocławskiego, 2002.

Kuznecov, Sergej. Bol'šoj tolkovyj slovar' russkogo âzyka. Web 19.09.2019. http://gramota.ru/slovari/info/bts/.

Lewicki, Roman. Chrześcijaństwo: słownik rosyjsko-polski. Warszawa, Instytut Wydawniczy Pax, 2002.

Markunas Antoni, Uczitiel Tamara. Leksykon chrześcijaństwa: rosyjsko-polski i polsko-rosyjski. Poznań, Wydawnictwo Naukowe UAM, 1999.

Mirowicz, Anatol et al. Wielki słownik rosyjsko-polski. Warszawa, Wiedza Powszechna, 1993.

Novyj slovar' inostrannyh slov. Web 20.10.2019. http://www.slovari.ru/search.aspx?s=0\&p=3068.

Pravoslavnaâ ènciklopediâ. Red. Patriarh Moskovskij i vseâ Rusi Kirill. Web 21.10.2019. http:// www.pravenc.ru/.

Rim i Vatikan. Sobor Svâtogo Petra - Basilica di San Pietro. Web 20.10.2019. http://in-rome.ru/ attractions/sobor-sv-petra.html.

Szałek, Marek. Słownik homonimów rosyjsko-polskich. Poznań, Ars Nova, 2004.

Sztolberg-Bybluk, Mirosława. Podręczny stownik rosyjsko-polski i polsko-rosyjski terminów chrześcijańskich. Toruń, Wydawnictwo Naukowe UMK, 1994.

\section{Сокращения}

BTSRÂ - Kuznecov, Sergej. Bol'šoj tolkovyj slovar' russkogo âzyka. Web 19.09.2019. http://gramota.ru/slovari/info/bts/.

ChRPS - Lewicki, Roman. Chrześcijaństwo: stownik rosyjsko-polski. Warszawa, Instytut Wydawniczy Pax, 2002.

ÈSRÂ - Fasmer, Maks. Ėtimologičeskij slovar' russkogo âzyka. Per. i dop. Oleg Trubačev. Moskva, Progress, 1971. 
LCh - Markunas, Antoni, Tamara Uczitiel. Leksykon chrześcijaństwa: rosyjsko-polski i polsko-rosyjski. Poznań, Wydawnictwo Naukowe UAM, 1999.

NSIS - Novyj slovar' inostrannyh slov. Web 20.10.2019. http://www.slovari.ru/search. aspx? $=0 \& \mathrm{p}=3068$.

WSPR - Hessen, Dymitr, Ryszard Stypuła. Wielki słownik polsko-rosyjski, t. I, II. Warszawa, Wiedza Powszechna, 1996.

WSRP - Mirowicz, Anatol et al. Wielki stownik rosyjsko-polski, t. I, II. Warszawa, Wiedza Powszechna, 1993. 